\title{
Acquired Cutaneous Lymphangiectasia: Dermoscopic Evidence from White-Yellowish Lacunae
}

Nicolás Silvestre-Torner ${ }^{1}$, Adrián Imbernón-Moya ${ }^{1}$, Marta Martínez-García ${ }^{1}$, Fernando BurgosLázaro $^{2}$

1 Department of Dermatology. Hospital Universitario Severo Ochoa. Avenida de Orellana, Leganés, Madrid, Spain. 2 Department of Pathology. Hospital Universitario Severo Ochoa. Avenida de Orellana, Leganés, Madrid, Spain.

Key words: Lymphangiectasia, Dermoscopy, Lymphedema, Breast cancer

Citation: Silvestre-Torner N, Imbernón-Moya A, Martínez-García M, Burgos-Lázaro F. Acquired cutaneous lymphangiectasia: dermoscopic evidence from white-yellowish lacunae. Dermatol Pract Concept. 2021;11(3):e2021062. DOI: https://doi.org/10.5826/dpc.1103a62

Accepted: December 10, 2020; Published: July 8, 2021

Copyright: (92021 Silvestre -Torner et al. This is an open-access article distributed under the terms of the Creative Commons Attribution License BY-NC-4.0, which permits unrestricted noncommercial use, distribution, and reproduction in any medium, provided the original authors and source are credited.

Funding: None.

Competing interests: The authors have no conflicts of interest to disclose.

Authorship: All authors have contributed significantly to this publication.

Corresponding author: Nicolás Silvestre Torner, Department of Dermatology, Hospital Universitario Severo Ochoa, Avenida de Orellana, Leganés, Madrid, Spain, Plaza General Vara de Rey 11, 4G. Email: nicolassilvestretorner@gmail.com

\section{Case Presentation}

A 71-year-old woman, with a personal history of a left radical mastectomy and locoregional radiation therapy for breast cancer 20 years ago, was referred for assessment. She presented secondary chronic upper limb lymphedema and asymptomatic flesh-colored papulovesicles on the left axillary area (Figure 1) that appeared 6 months ago. On dermoscopy, lesions presented well-demarcated red-orange lacunae surrounded by white lines (Figure 2). Histopathology showed multiple ectatic lymphatic vessels in the papillary dermis (Figure 3). Thus, a diagnosis of acquired cutaneous lymphangiectasia was made.

\section{Teaching Point}

Acquired cutaneous lymphangiectasia (ACL) are dilatations of surface lymphatic vessels, following lymphatic damage after surgery or radiotherapy, specially related with breast cancer [1]. Often described as "frog spawn", ACL presents as multiple asymptomatic translucent vesicular lesions, resembling a lymphangioma circumscriptum. Dermoscopy shows a vascular pattern with yellow-orange lacunae surrounded by white septa [2]. Although ACL are considered benign disorders, histopathological diagnosis is needed to rule out different disorders, including cutaneous metastases from previous cancers. 


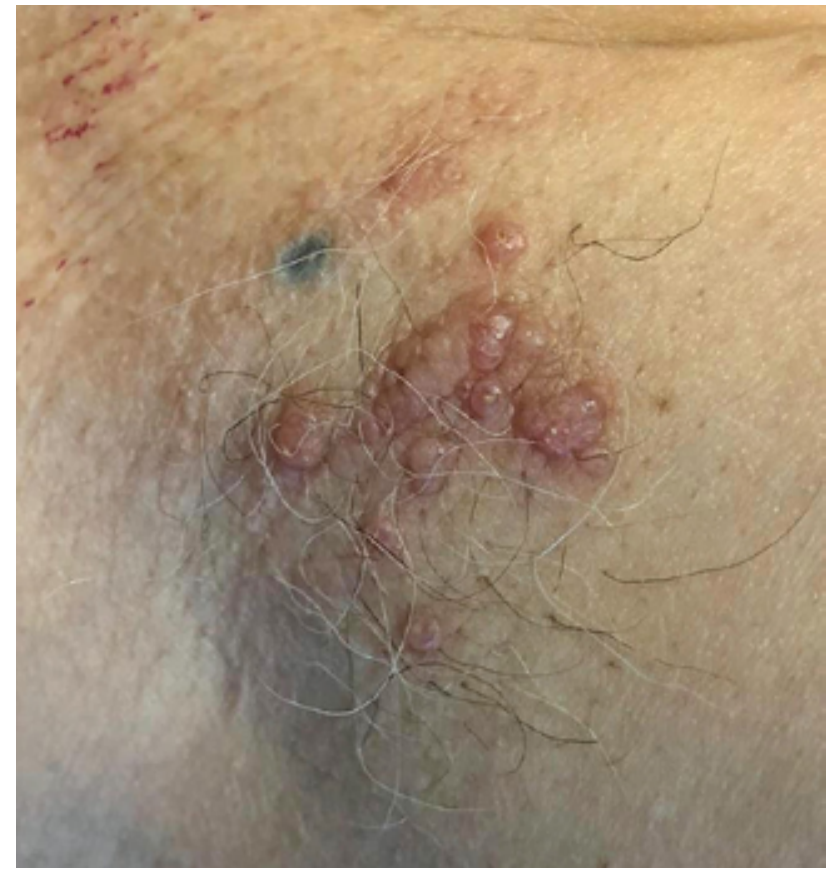

Figure 1. Multiple thin-walled papulovesicles on the left axillary area.

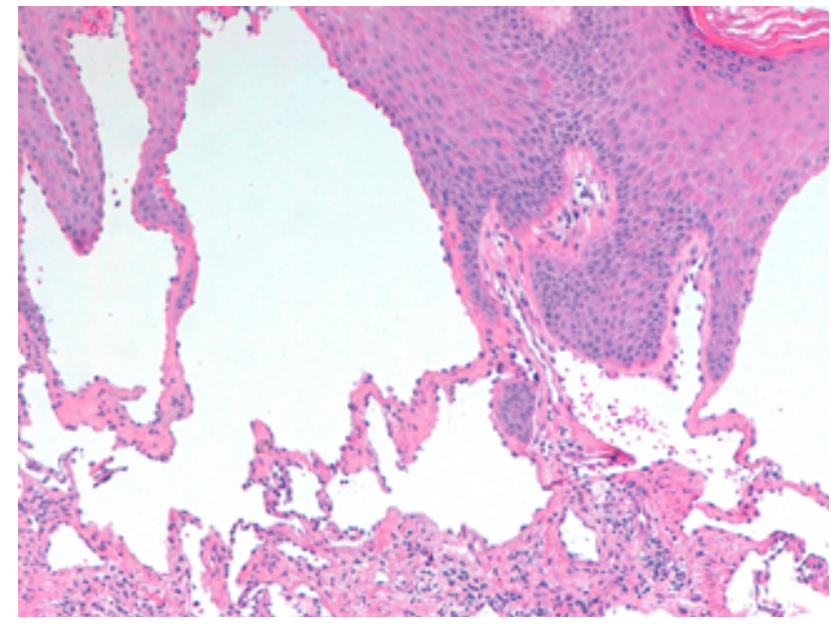

Figure 3. Histopathology revealing ectatic vessels in papillary dermis lined by a single layer of endothelial cells.

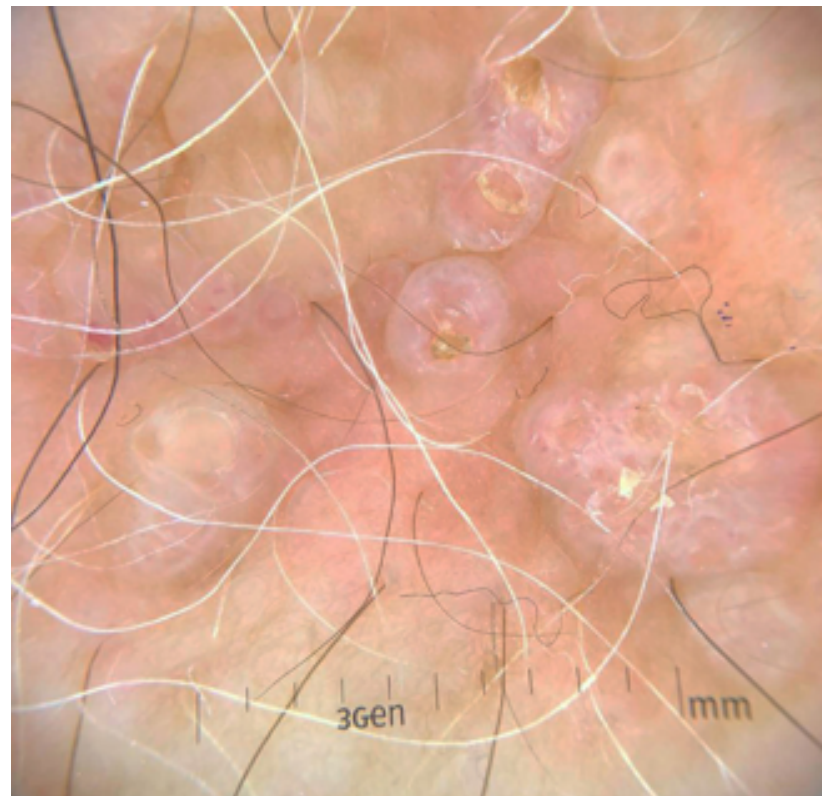

Figure 2. Dermoscopy revealing a vascular pattern with well-circumscribed yellowish lacunae surrounded by pale septa.

\section{References}

1. Valdés F, Peteiro C, Toribio J. Acquired Lymphangiectases and Breast Cancer. Actas Dermo-Sifiliográficas (English Edition). 2007;98(5):347-350. DOI:10.1016/S1578-2190(07)70459-6

2. Verzì AE, Lacarrubba F, Tedeschi A, Micali G. Localized acquired lymphangiectasias after breast surgery: Enhanced non-invasive diagnosis using dermoscopy and reflectance confocal microscopy. Skin Res Technol. 2020;26(2):205-208. DOI:10.1111/srt.12780. PMID: 31549745 